\title{
Using the ASSIST Model to Improve Health and Wellness Adherence and Outcomes
}

\author{
Park Lockwood* \\ Department of Kinesiology, USA
}

*Corresponding author: Park Lockwood, Associate Professor, Kinesiology Department, USA.

Received Date: July 31, 2019

Published Date: August 09, 2019

\begin{abstract}
There appears to be an assumption that when a medical professional tells patients they need to exercise, eat right, reduce stress, improve sleep, stop smoking, or somehow generally improve their health habits, these patients have the knowledge and skills to adhere to this instruction. In fact, most people do not have the knowledge, skills, and experience to carry out such a complex behavioral change [1,2]. Proper guidance from a multidisciplinary team of health and wellness professionals, however, can create a bridge that leads to the knowledge and skills necessary to achieve behavior change. In addition, this type of change can be even more difficult in lower-income, underserved populations [3]. People who fall into this category typically do not have the resources (professional guidance, medication, physical therapy, counseling, etc.) to make healthy changes [3]. It is this gap between information and behavior change that may prevent many people from starting and maintaining a healthy lifestyle.

Recently, Washburn University in Topeka, Kansas has implemented a university-housed wellness program that uses the basic humanistic principles of guidance, support, compassion, and perseverance to successfully help individuals with a lower income make important health changes in their lives. The model used for this program is called ASSIST (Affordable, Social Support, Structure, Integration, Screening, and Time), and has been quite successful in helping people adhere to their programs and improve their health and quality of life.
\end{abstract}

\section{The Assist Model}

Based on previous research as well as trial-and-error knowledge and experience attained from the development of previous wellness programs at clinical sites, there have been certain criteria identified that are important factors in creating and maintaining a successful wellness program [4-7]. In sum, the acronym ASSIST (Affordable, Social support, Structure, Integration, Screening, and Time) has been used as a guide to be developing and maintaining this wellness program. First, this program is affordable. In discussions with clientele, most say they can't afford these types of services within the community. Clients of lower socioeconomic status need to be able to participate at low or no cost, as those who do not have the financial resources for basic functional and medical needs are not likely to pay for preventive healthcare $[3,8,9]$. The program is sustained by community and university grants, departmental funds, student interns, and a volunteer program. All services are provided at no cost.

There is a significant amount of social support for the participants in the program. Research has shown that consistent feedback and education from professionals and peers help clients adhere to their behavior change and eventually internalize their new behavior [10]. Using a step-by-step process and providing a compassionate and accepting environment help prevent new clients from feeling intimidated and, in fact, help provide a "safe" place that further enhances the behavior change process. Regular meetings are scheduled with clients to discuss progress, provide feedback, review goals, and discuss any relevant issues with their program. Employees interact with clients at each visit to inquire about their health status, make necessary adjustments to their program, or simply be an active listener and play a supportive role. Programs are very structured. It is well documented that those who have never developed healthy boundaries and structure in their lifestyle habits must develop this in order to make change [2]. Follow-up appointments are rescheduled with each visit. Staff discuss goals and behaviors. Nutrition and weight management programs are documented and reviewed, exercise and stress management activities are recorded and reviewed, and physiological measurements such as blood pressure and resting heart rate are assessed. Clients who miss an appointment are immediately contacted to reschedule. Wellness staff assess, review, 
and interact with clients on a regular basis and continue to guide them through their program, gradually shifting responsibility for completing program activities to the clients themselves.

Knowledge and information from various disciplines must be integrated into the treatment protocols [11,7]. For example, students and faculty in the areas of Kinesiology, Nursing, Social Work, Physical Therapy, Psychology, and Law are included in order to formulate a well-rounded wellness program. Kinesiology provides expertise in developing fitness, nutrition, and weight management programs. Nursing faculty and students consult with clients who have medical and/or medication issues. Those who seek counseling are referred to individual or group counseling via the Psychology Department and / or the university Counseling Clinic. Physical Therapy is consulted for rehabilitation issues. Social work provides support for clients with basic economic and functional issues, and clients are referred to the university Law Clinic for basic legal issues. In order to monitor client changes and program success, screening/ assessment is completed at regular intervals. Assessment occurs at the initial visit and one, three, six, and 12 months into the program. Additional assessments occur every six months upon completing the first year of the program. The outcomes assessed include perceived health, program adherence, program satisfaction, weight loss, aerobic capacity, upper and lower body strength and endurance, and physiological changes (i.e., blood pressure, glucose, cholesterol, and triglycerides). These assessments provide a means to evaluate the progress of individual clients as well as aggregate data to evaluate program success. Finally, enough time must be provided so clients can appropriately progress through the behavior change process [2]. Most clients enter this program with lifestyle habits that have contributed to their chronic conditions, so these habits are certainly difficult to change in a short period of time. After repeated exposure to new, healthier habits, actual change is not likely to occur for at least six months [2]. Employees provide educational, support, and motivational strategies to help clients persevere and progress through the stages of change over time.

\section{Program Outcomes}

The success of this model was determined by analyzing the psychological, physiological, and physical outcome variables from clientele who utilized this program. For clientele who participated in this program for a minimum of six months, adherence was $77 \%$ and program satisfaction was $95 \%$. That is when asked how satisfied clients are with this program on a scale of 1-10, most reported a 9 or 10 . As for the adherence rate, it is relatively high compared to similar programs which average closer to $60 \%$ [12]. In addition, perceived health improved 17\% (61 - 78) as measured by the Health Visual Analog Scale (VAS), behavior change improved by an average of 2.5 stages, aerobic capacity increased by $8 \mathrm{ml} / \mathrm{kg} /$ $\min (30-38 \mathrm{ml} / \mathrm{kg} / \mathrm{min}$ ), resting heart rate lowered by $5 \mathrm{bpm}$ (73$68 \mathrm{bpm})$, clients reduced their weight by an average of 17 pounds (206-189 lbs.), and BMI decreased by 3 points (36-33). Blood pressure (134/79 - 127/74 mm/hg), total cholesterol (165 - 156 $\mathrm{mg} / \mathrm{dL}$, triglycerides (144 - $128 \mathrm{mg} / \mathrm{dL})$, and glucose (114 - 100 $\mathrm{mg} / \mathrm{dL}$ ) decreased while HDL (46 - $49 \mathrm{mg} / \mathrm{dL})$ increased. Upperand lower- body muscular endurance (push-ups 14-22; wall sit 42 - 70 sec.) as well as functional fitness (15 - 24 sit-and-stands) also improved.

When the adherence rate, program satisfaction, and improved outcomes are taken into account; it is easy to see that this program has been highly successful in improving the health and wellness of its clientele. The fundamental aspect of this program that makes it unique is the use of the ASSIST model. The ASSIST model is a useful template for implementing and maintaining a multidisciplinary wellness program that provides clients the opportunity to improve their health and wellness. It utilizes the many humanistic and structural components that guide and support people through the process of changing their behavior to create a healthier lifestyle. In doing so, it forms the basis for assisting a population that is unable to access or afford these types of services, it integrates the knowledge and skills from multiple disciplines, and it establishes a working model to help people permanently alter their health behaviors.

\section{Acknowledgements}

None.

\section{Conflict of Interest}

No conflict of interest.

\section{References}

1. Gronhaug G (2017) Addressing the elephant in the room: a possible new way to increase patient adherence to medical advice. Patient Prefer Adherence 11: 1083-1089.

2. Ligouri G, Carroll Cobb S (2012) Introduction to health, wellness, and fitness. In: McGraw-Hill, New York.

3. Stonerock GL, Blumenthal JA (2017) Role of counseling to promote adherence in healthy lifestyle medicine: strategies to improve exercise adherence and enhance physical activity. Prog Cardiovasc Dis 59(5): 455-462.

4. Barnard S, Dunn S, Reddic E, Rhodes K, Russell, Tuitt TS, et al. (2004) Tillery: A Community-Built Program. Fam Community Health 27(2): 154-157.

5. Dierich M (2007) Adventures in Health Care: Designing a Wellness Center for Low-Income Elders. Urol Nurs 27(5): 403-408.

6. Harrison RL, Mattson LK, Durbin DM, Fish AF, Bachman JA (2012) Wellness in Community Living Adults: The Weight to Life Program. Patient Educ Couns 86(2): 270-276.

7. Wohl RE, Lockwood P, Ure K (2017) A Multi-Disciplinary Approach to Establishing a Community Wellness Program. Kinesiology Review 6(4): 329-334.

8. Merrill RM, Hull JD (2012) Factors associated with participation in and the benefits of a worksite wellness program. Popul Health Manag 16(4): 221-226.

9. Shapiro V, Moseley K (2013) The real value of wellness programs: A comprehensive review of the literature. Popul Health Manag 16(4): 283284.

10. Kaspin LC, Gorman KM, Miller RM (2013) Systematic review of employer-sponsored wellness strategies and their economic and healthrelated outcomes. Popul Health Manag 16(1): 14-21. 
11. Kupchella CE (2009) Colleges and universities should give more broadbased attention to health and wellness - at all levels. J Am Coll Health 58(2): 185-186.
12. Lemstra M, Bird Y, Nwankwo C, Rogers M, Moraros J (2016) Weight loss intervention adherence and factors promoting adherence: a metaanalysis. Patient Prefer Adherence 10: 1547-1559. 